\title{
Assessment of ventricular diastolic function in AIDS patients from Congo: a Doppler echocardiographic study
}

\author{
B Longo-Mbenza, L V Seghers, E Kintoki Vita, K Tonduangu, M Bayekula
}

\begin{abstract}
Objective-To investigate the prevalence of left ventricular dysfunction in African patients infected with the human immunodeficiency virus (HIV). The hypothesis was that HIV infected patients with left ventricular dysfunction are asymptomatic.

Methods-M mode, cross sectional, and Doppler echocardiography were performed in 49 consecutive patients (30 HIV positive (HIV+) carriers and 19 AIDS patients). None of the patients or 58 controls had a medical history of cardiovascular abnormalities.

Results-Cardiac abnormalities were not suspected on physical, electrocardiographic, and radiological examination. Forty two of the HIV infected patients had left ventricular diastolic dysfunction; this was more pronounced in AIDS patients than in HIV+ carriers. Systolic function was normal in both stages of HIV infection. Left ventricular isovolumic relaxation time (mean (SD)) increased from $87.2(12.4) \mathrm{ms}$ in the carrier state to 103.9 (19.3) $\mathrm{ms}$ in AIDS $(p<0.05$, Bonferoni correction), peak early filling velocity declined from $0.54(0.1)$ to $0.44(0.1) \mathrm{m} / \mathrm{s}$ $(p<0.05)$, and late velocity increased from $0.64(0.1)$ to $0.69(0.2) \mathrm{m} / \mathrm{s}$. A restrictive filling pattern was explained by concentric hypertrophy in 23 HIV infected patients, and by systemic amyloidosis with left ventricular dilatation in 12 of $49 \mathrm{HIV}$ infected patients.

Conclusions-Echocardiography is a useful technique for detecting left ventricular diastolic dysfunction in HIV infected patients with clinically unsuspected cardiac lesions. Systolic function was normal despite the presence of such cardiac abnormalities.

(Heart 1998;80:184-189)
\end{abstract}

Keywords: HIV infection; AIDS; diastolic dysfunction; black Africans; echocardiography

AIDS has been recognised and defined only within the past decade or so. ${ }^{1}$ With their profound immunosuppression, AIDS patients are predisposed to multiple opportunistic infections and malignancies. ${ }^{2}{ }^{3}$ The clinical and pathological features in the respiratory, tegumentary, gastrointestinal, haematological, renal, and neurological systems have been well characterised in the setting of human immunodeficiency virus type 1 (HIV-1) infection. ${ }^{4-7}$

Various forms of cardiac impairment in patients suffering from AIDS have been reported, such as myocarditis and cardiomyopathies. ${ }^{8}$ In Africa, there is evidence that HIV may affect the heart, ${ }^{29}$ and left ventricular dysfunction appears to be common, though we believe that affected individuals are often asymptomatic. The aim of our study was to determine the prevalence of left ventricular diastolic dysfunction in African patients with HIV.

\section{Methods}

PATIENTS

We studied a consecutive series of 49 patients (29 men and 20 women, age 20 to 50 years, mean (SD) 28 (6.4) years) with positive HIV serology and a clinical diagnosis of HIV infection according to CDC criteria, ${ }^{10}$ and 58 seronegative control subjects. All were black and all gave informed consent to the study. Infected patients were classified as group I (30 patients, HIV infection stage A-1) and group II (19 patients, AIDS stage C1 (CDC)). Group III (58 subjects)-blood donors-comprised the controls ( 30 men and 28 women, age 22 to 48 years, mean 29 (4) years).

The 49 patients (groups I and II) with HIV infection were referred for examination to the Centre of Cardiology, Lomo Medical, Kinshasa Limete, from December 1988 to April 1993.

Clinical assessment included physical examination, electrocardiography (ECG), chest radiography, and Doppler echocardiographic examination. Blood was drawn for haemoglobin measurement, erythrocyte sedimentation rate (ESR), CD4 count (performed by a slide technique with APAAP mouse monoclonal antibody (Dako, Glostrup, Denmark)), and HIV serology control. Antibody levels against HIV were measured by an enzyme linked immunosorbent assay and confirmed by western blotting. Subjects with hypertension, pericardial effusion, ischaemic heart disease, cardiomyopathy (hypertrophic or diabetic), and chronic bronchopulmonary disease were excluded. None of the subjects was known to be homosexual or a drug misuser. The patients were not on any medication at the time of examination. Dyspnoea alone was not a reason for exclusion, because it is a relatively common complaint in AIDS (associated with opportunistic diseases). Renal and gingival biopsies were performed in the $21 \mathrm{HIV}$ positive carriers $(71 \%)$ who had proteinuria. 
Table 1 Clinical and sonographic features of HIV infected patients and controls

\begin{tabular}{|c|c|c|c|c|c|}
\hline Variables & $\begin{array}{l}\text { HIV+ carriers } \\
(n=30)\end{array}$ & $\begin{array}{l}\text { AIDS patients } \\
(n=19)\end{array}$ & $\begin{array}{l}\text { Controls } \\
(n=58)\end{array}$ & $\begin{array}{l}\text { p values } \\
\text { (Mann- } \\
\text { Whitney U, } \\
\text { ANOVA) }\end{array}$ & $\begin{array}{l}\text { Bonferoni } \\
\text { correction }\end{array}$ \\
\hline $\begin{array}{l}\text { Age (years) } \\
\text { Heart rate }\end{array}$ & $27(4)$ & $28(4)$ & $29(4)$ & NS & \\
\hline $\begin{array}{l}\text { Heart rate } \\
\text { (beats/min) }\end{array}$ & $81.6(10.3)$ & $80.7(7.9)$ & $74.9(11.3)$ & NS & NS \\
\hline $\operatorname{LVMI}\left(\mathrm{g} / \mathrm{m}^{2}\right)$ & $119(26)$ & $147(28)$ & $112(15)$ & $\begin{array}{l}\mathrm{p}<0.05^{\star} \\
\mathrm{p}<0.05 \dagger \\
\mathrm{p}<0.05 \ddagger\end{array}$ & $1 \mathrm{v}$ \\
\hline $\mathrm{SBP}(\mathrm{mm} \mathrm{Hg})$ & $128.8(11.9)$ & $132.4(12.6)$ & $130.8(11.6)$ & NS & NS \\
\hline $\mathrm{DBP}(\mathrm{mm} \mathrm{Hg})$ & $78.6(8.8)$ & $80.2(6.8)$ & $77.8(7.4)$ & NS & NS \\
\hline LVEDD $(\mathrm{cm})$ & $5.8(1.2)$ & $6.8(1.5)$ & $5.1(0.9)$ & & $\begin{array}{l}\mathrm{p}<0.05^{\star} \\
\mathrm{p}<0.05 \dagger \\
\mathrm{p}<0.05 \ddagger\end{array}$ \\
\hline $\begin{array}{l}\mathrm{VE}(\mathrm{m} / \mathrm{s}) \\
(95 \% \mathrm{CI})\end{array}$ & $\begin{array}{l}0.54(0.1) \\
(0.48 \text { to } 0.59)\end{array}$ & $\begin{array}{l}0.44(0.1) \\
(0.39 \text { to } 0.48)\end{array}$ & $\begin{array}{l}0.84(0.1) \\
(0.59 \text { to } 0.88)\end{array}$ & $<0.001$ & $\begin{array}{l}\mathrm{p}<0.05^{\star} \\
\mathrm{p}<0.05 \dagger \\
\mathrm{p}<0.05 \ddagger\end{array}$ \\
\hline $\begin{array}{l}\text { VA (m/s) } \\
(95 \% \mathrm{CI})\end{array}$ & $\begin{array}{l}0.64(0.1) \\
(0.60 \text { to } 0.68)\end{array}$ & $\begin{array}{l}0.69 \\
(0.63 \text { to } 0.72)\end{array}$ & $\begin{array}{l}0.58(0.1) \\
(0.56 \text { to } 0.60)\end{array}$ & $<0.001$ & $\begin{array}{l}\mathrm{p}<0.05^{\star} \\
\mathrm{p}<0.05 \dagger \\
\mathrm{p}<0.05 \ddagger\end{array}$ \\
\hline VE/VA ratio & $0.54(0.2)$ & $0.64(0.1)$ & $1.4(0.2)$ & $<0.001$ & $\begin{array}{l}\mathrm{p}<0.05^{\star} \\
\mathrm{p}<0.05 \dagger \\
\mathrm{p}<0.05 \ddagger\end{array}$ \\
\hline $\begin{array}{l}\text { DHT (ms) } \\
(95 \% \mathrm{CI})\end{array}$ & $\begin{array}{l}89(12) \\
(83 \text { to } 94)\end{array}$ & $\begin{array}{l}106(20) \\
(96 \text { to } 113)\end{array}$ & $\begin{array}{l}80(12) \\
(76 \text { to } 85)\end{array}$ & $<0.001$ & $\begin{array}{l}\mathrm{p}<0.05^{\star} \\
\mathrm{p}<0.05 \dagger \\
\mathrm{p}<0.05 \ddagger\end{array}$ \\
\hline $\begin{array}{l}\text { IVRT (ms) } \\
(95 \% \mathrm{CI})\end{array}$ & $\begin{array}{l}87.2(12.4) \\
(74 \text { to } 100)\end{array}$ & $\begin{array}{l}103.9(19.3) \\
(80 \text { to } 126)\end{array}$ & $\begin{array}{l}79.4(12) \\
(73 \text { to } 82)\end{array}$ & $<0.001$ & $\begin{array}{l}\mathrm{p}<0.05^{\star} \\
\mathrm{p}<0.05 \dagger \\
\mathrm{p}<0.05 \ddagger\end{array}$ \\
\hline
\end{tabular}

Values are mean (SD).

*AIDS $v$ HIV+ carriers; +HIV+ carriers $v$ controls; $\neq$ AIDS $v$ controls.

DBP, diastolic blood pressure; DHT, deceleration half time; IVRT, isovolumic relaxation time; LVEDD, left ventricular end diastolic diameter; LVMI, left ventricular mass index; SBP, systolic blood pressure; VA, peak late velocity; VE, peak early velocity.

Findings from necropsies were available in 16 AIDS patients $(84.2 \%)$, three performed in Kinshasa and 16 abroad; details have been reported previously. ${ }^{11}$ Because of the lack of equipment, ventricular compliance data, invasive data, and apex cardiographic data were not available.

M MODE, CROSS SECTIONAL, AND DOPPLER ECHOCARDIOGRAPHIC EXAMINATION

$M$ mode, cross sectional, and pulsed wave Doppler echocardiographic examinations were performed with a Genesis ultrasonoscope with a $2.5 \mathrm{MHz}$ wide angle phased array transducer. (Biosound, Indianapolis, Indiana, USA). Patients were laid in the left lateral position and examined in standard parasternal long and short axis and apical views.

Using the cross sectional images as a guide, the $M$ mode tracing of the left ventricle was obtained to calculate measurements according to the recommendations of the American Society of Echocardiography. ${ }^{12}$ The following variables were measured: left ventricular end diastolic and end systolic dimensions, interventricular septal and left ventricular posterior wall thickness in diastole for calculating left ventricular mass (Devereux's formula), left ventricular shortening (FS\%), early peak velocity (VE), late peak velocity (VA), systolic time intervals, VE/VA ratio, isovolumic relaxation time (IVRT), and deceleration half time of the early filling period (DHT). Three cycles were analysed and average values were calculated.

The IVRT is the interval from the closure of the aortic valve until mitral valve opening. It maybe measured by simultaneous phonocardiography (to record the aortic closure sound) and pulsed Doppler (to detect the onset of mitral flow), or by continuous wave imaging from the apical window, displaying aortic and mitral flow together, as in the present study. The mean (SD) normal IVRT value is 71 (14) ms.

The mitral deceleration time (DT) is the time period from the peak of the VE wave until the end of early diastolic filling (normal mean value 199 (32) ms).

Pulsed Doppler pulmonary vein flow was measured at the left atrial opening from a four chamber apical window.

Normal values for other variables are as follows: VE, $0.86(0.16) \mathrm{ms}$; VA, $0.56(0.13) \mathrm{ms}$; VE/VA ratio, $1.6(0.4)$; left ventricular mass index, $110-134 \mathrm{~g} / \mathrm{m}^{2}$; left ventricular end diastolic dimension (LVEDD), $<5.5 \mathrm{~cm}$; and FS $\%>28 \%$.

Left (or right) ejection time (LVET, RVET) was measured from aortic (or pulmonary) valve opening to aortic valve closure (normal, 309 (41) ms). Left (or right) ventricular pre-ejection period (LVPEP, RVPEP) was measured as the interval from valve opening (normal, 99 (14) ms). Left ventricular isovolumic contraction time (LVICT) was the interval between coaptation of the anterior and posterior mitral valve leaflets and aortic valve opening (normal, 38 (10) $\mathrm{ms}$ ).

STATISTICAL ANALYSIS

Data are expressed as mean (SD) and compared between the AIDS patients and the normal controls. Significant differences between the groups were determined using the MannWhitney U test, $2 \times 2$ contingency table analysis, and Fisher's exact test. Probability (p) values were corrected for multiple comparisons by the Bonferoni correction. Linear regression analyses were performed to assess the relations between cardiac measurements and different variables.

\section{Results}

Physical examination, electrocardiographic data, blood pressure levels, and systolic function were normal in all three groups. The AIDS patients, the HIV positive carriers, and the control subjects were in sinus rhythm with a heart rate $<96$ beats/min. Nutritional status was normal in 40 patients (30 HIV positive carriers and 10 AIDS patients with a body mass index $\geqslant 25 \mathrm{~kg} / \mathrm{m}^{2}$ ), while nine women with AIDS presented with a moderate wasting syndrome (BMI $16(2.5) \mathrm{kg} / \mathrm{m}^{2}$ ).

Assessments of left ventricular diastolic function and left ventricular mass variations are summarised in table 1 . Left ventricular diastolic dysfunction was accompanied by left ventricular hypertrophy and was more pronounced in AIDS patients than in HIV positive carriers. The differences were significant.

HIV infected individuals had no change in left ventricular isovolumic relaxation time with respiration.

There were significant differences in echocardiographic findings in the patients with HIV infection (HIV positive carriers and AIDS patients) compared with the control group (table 2). Forty two $(85.7 \%)$ of the 49 patients with HIV infection had diastolic dysfunction, 
Table 2 Laboratory and echocardiographic characteristics of patients with HIV infection (groups I and II) and controls (group III)

\begin{tabular}{llll}
\hline Variables & $\begin{array}{l}\text { HIV infection } \\
(n=49)\end{array}$ & Controls $(n=58)$ & p value \\
\hline LVEDD > 5.5 cm $(\%(\mathrm{n}))$ & $24.4 \%(12)$ & $3.5 \%(2)$ & $<0.001$ \\
Septal wall thickness $(\mathrm{cm})^{\star}$ & $1.3(0.3)$ & $0.9(0.2)$ & $<0.001$ \\
Left atrial diameter $(\mathrm{cm})$ & $3.1(0.5)$ & $3(0.4)$ & $\mathrm{NS}$ \\
LV wall thickness $(\mathrm{cm})^{\star}$ & $1.33(0.4)$ & $1(0.3)$ & $<0.05$ \\
VE $(\mathrm{m} / \mathrm{s})$ & $0.51(0.1)$ & $0.84(0.1)$ & $<0.001$ \\
VA $(\mathrm{m} / \mathrm{s})$ & $0.64(0.1)$ & $0.58(0.1)$ & $<0.05$ \\
Diastolic dysfunction & $85.7 \%$ & $13.8 \%$ & $<0.001$ \\
& $(\mathrm{n}=42)$ & $(\mathrm{n}=8)$ & \\
Concentric LV hypertrophy & $46.9 \%$ & $6.9 \%$ & $<0.001$ \\
& $(\mathrm{n}=23)$ & $(\mathrm{n}=4)$ & $<0.05$ \\
Haemoglobin $(\mathrm{g} / \mathrm{l})$ & $104(12)$ & $134(16)$ & $<0.05$ \\
ESR $(\mathrm{mm}$ in $1 \mathrm{st} \mathrm{hour})$ & $39.2(5.0)$ & $25.0(4.0)$ & $<0.001$ \\
CD4+ count $\left(/ \mathrm{mm}^{3}\right)$ & $233(57)$ & $1043(112)$ & \\
\hline
\end{tabular}

Values are mean (SD) except where specified.

*In diastole.

ESR, erythrocyte sedimentation rate; LV, left ventricular; LVEDD, left ventricular end diastolic diameter; VA, peak late velocity; VE, peak early diastolic velocity.

$23(46.9 \%)$ had concentric left ventricular hypertrophy, and $12(24.4 \%)$ had left ventricular dilatation; in the control group the respective values were eight $(13.8 \%)$, four $(6.9 \%)$, and two $(3.5 \%)(\mathrm{p}<0.001)$. Ten $(52.6 \%)$ of the patients in the AIDS group had left ventricular dilatation compared with only two of $30(6.6 \%)$ in the HIV positive group $(\mathrm{p}<0.001)$. Posterior wall thickness was greater in AIDS patients than in HIV positive carriers, at $14.6(2.3) v 11.5(2.5) \mathrm{mm})$ $(\mathrm{p}<0.05)$. However, nine women of the 30 HIV positive carriers $(30 \%)$ had some degree of cardiac atrophy.

In none of the HIV positive carriers, AIDS patients, or control subjects was dyspnoea present at more than New York Heart Association grade I-II. There was no clinical evidence of congestive heart failure in any individual in the study population on physical examination. Haemoglobin and CD4+ count were lowest in patients with HIV infection. Erythrocyte sedimentation rate rose significantly with HIV infection.

Pulmonary vein pulsed Doppler findings in HIV positive carriers, AIDS patients, and the control group showed preservation of normal pulmonary venous flow, with an ejection fraction of around $40 \%$. The systolic (J) flow was larger than the diastolic $(\mathrm{K})$ flow. There was no valve regurgitation on Doppler examination.

Necropsy in 16 AIDS patients showed lesions of acute myocarditis with lymphocytic infiltrates and Toxoplasma gondii in three, Cryptococcus neoformans in three, Mycobacterium avium in two, and HIV in eight. Amyloidosis was present in $66.6 \%$ of 21 HIV positive carriers on gingival and renal biopsies. Men had a significantly greater left ventricular mass index than women at all stages of HIV positive carrier state and AIDS, whereas the values were similar in HIV seronegative men and women (table 3). When compared to the control group, HIV positive carriers and AIDS patients had a significant decrease in peak VE velocity, deceleration time, and VE/VA ratio, and a significant increase in VA wave (fig 1). Right ventricular systolic time intervals in HIV infected patients were not different from control values, but left ventricular ejection time was prolonged in HIV
Table 3 Distribution of left ventricular mass index (LVMI) with respect to sex and HIV immune status

\begin{tabular}{llll}
\hline & Women & Men & p value \\
\hline HIV negative (n) & 13 & 15 & \\
LVMI $\left(\mathrm{g} / \mathrm{m}^{2}\right)$ & $104.9(9.3)$ & $105.1(8)$ & NS \\
HIV+ carriers (n) & 11 & 19 & \\
LVMI $\left(\mathrm{g} / \mathrm{m}^{2}\right)$ & $128(2.9)$ & $157.9(54.1)$ & $<0.001$ \\
AIDS $(\mathrm{n})$ & $9^{\star}$ & 10 & \\
LVMI $\left(\mathrm{g} / \mathrm{m}^{2}\right)$ & $58.5(12.6)$ & $122.3(48)$ & $<0.001$
\end{tabular}

Values are mean (SD).

*Moderate undernutrition.
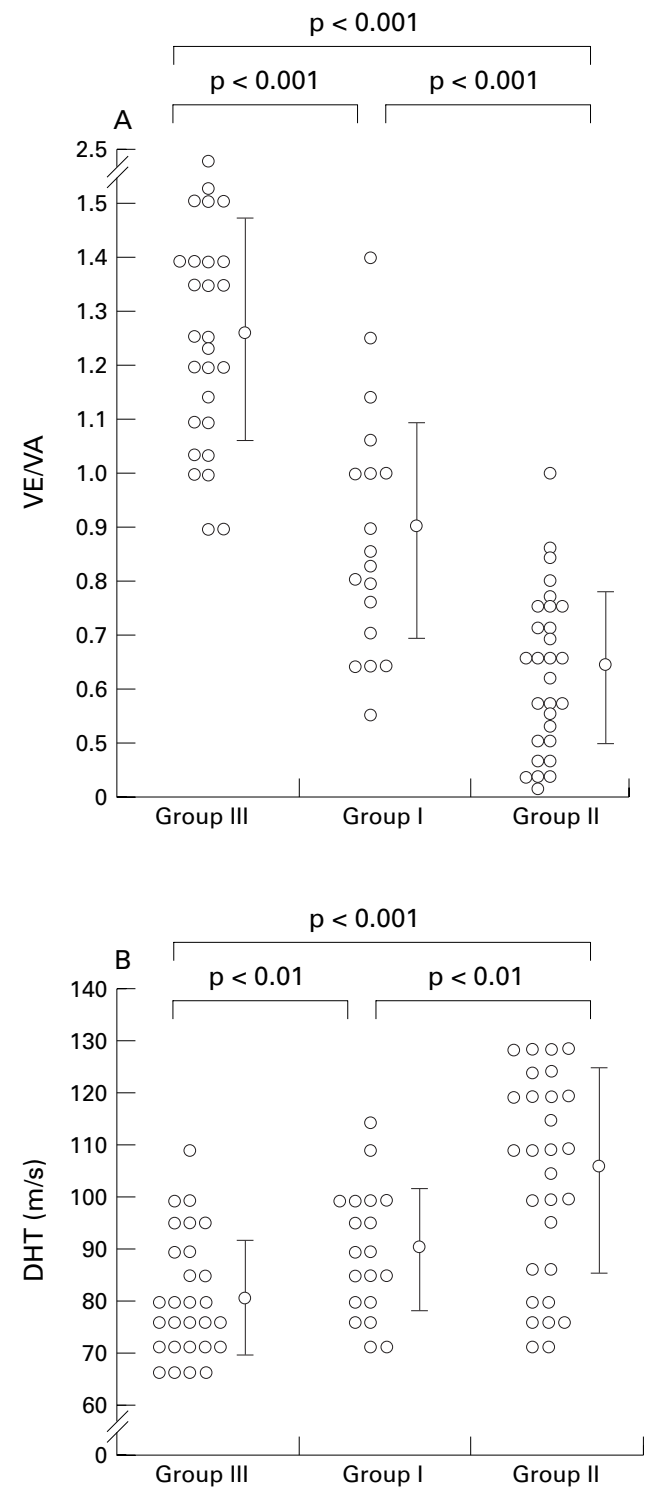

Figure 1 Comparison of early peak velocity (VE) to late peak velocity (VA) ratio and deceleration half time of the early filling period (DHT) between the groups.

infected patients (table 4 ). The velocity of circumferential fibre shortening and the ratio of left ventricular pre-ejection time to ejection time were lower in HIV infected patients than in the control group. Shortening fraction was normal in both HIV infected patients and HIV seronegative controls.

Other noteworthy findings from an analysis of pairwise correlations are given in table 5 . Left ventricular wall thickness was positively correlated with the velocity of circumferential fibre shortening (VCF) (systolic function). 
Table 4 Cardiac function assessed using systolic time intervals of patients with HIV infection (groups I and II) and in controls (group III)

\begin{tabular}{|c|c|c|c|}
\hline Variable & $\begin{array}{l}\text { HIV infection } \\
(n=49)\end{array}$ & $\begin{array}{l}\text { Controls } \\
(n=58)\end{array}$ & $p$ value \\
\hline RV pre-ejection (ms) & $92(23)$ & $88.4(22.3)$ & NS \\
\hline \multicolumn{4}{|l|}{ RV ejection time } \\
\hline$(\mathrm{ms})$ & $374(76.8)$ & $373(78)$ & NS \\
\hline RV ratio* & 0.246 & 0.237 & NS \\
\hline LV pre-ejection (ms) & $112(18)$ & $97.8(17.6)$ & $<0.001$ \\
\hline \multicolumn{4}{|l|}{ LV ejection time } \\
\hline (ms) & $377(61.4)$ & $307.6(40.8)$ & $<0.001$ \\
\hline LV ratio* & 0.229 & 0.317 & $<0.001$ \\
\hline \multicolumn{4}{|l|}{ Shortening fraction } \\
\hline$(\%)$ & $38.8(0$. & $39(0.06)$ & NS \\
\hline $\operatorname{VCF}(\mathrm{cm} / \mathrm{s})$ & $1.12(0.33)$ & $1.3(0.2)$ & $<0.05$ \\
\hline
\end{tabular}

Values are mean (SD)

* Ratio of pre-ejection time to ejection time.

$\mathrm{LV}$, left ventricular; RV, right ventricular; VCF, velocity of circumferential fibre shortening.

Table 5 Linear regression analysis of relations between haemodynamic and other variables in HIV infected patients

\begin{tabular}{llrl}
\hline Paired observations & & $r$ & $p$ value \\
& & & \\
LV wall & VCF & 0.38 & 0.04 \\
Septum & RV ejection time & -0.52 & 0.02 \\
LV pre-ejection & Heart rate & -0.19 & 0.04 \\
LV ejection time & LVEDD & 0.63 & 0.002 \\
LV ejection time & Heart rate & -0.21 & 0.02 \\
LV ratio & Shortening & -0.57 & 0.004 \\
& fraction & & \\
VCF & Haemoglobin & -0.50 & 0.01 \\
VCF & CD4 count & 0.19 & NS \\
Deceleration time & LV mass index & -0.337 & $<0.001$ \\
IVRT & LV mass index & 0.667 & $<0.001$ \\
DT & Heart rate & 0.078 & NS \\
IVRT & CD4 count & -0.734 & $<0.001$ \\
IVRT & Heart rate & -0.065 & NS \\
\hline
\end{tabular}

$\mathrm{LV}$, left ventricle; IVRT, isovolumic relaxation time; VCF, velocity of circumferential fibre shortening.

Septal thickness was inversely correlated with right ventricular ejection time. Left ventricular pre-ejection time and ejection time were inversely correlated with heart rate. Left ventricular ejection time was correlated with left ventricular chamber dimension. Left ventricular systolic time interval ratio was inversely related to shortening fraction. VCF was negatively related to haemoglobin concentration but positively to CD4+ count. Deceleration time (diastolic function) was correlated negatively with left ventricular mass index. Isovolumic relaxation time (diastolic function) was correlated positively with left ventricular mass index $(r=0.667, \mathrm{p}<0.001)$, but inversely with $\mathrm{CD} 4+$ count $\quad(r=-0.734$, $\mathrm{p}<0.001)$.

\section{Discussion}

During the last 12 years, interest in the management of diastolic dysfunction has been increasing. In Antwerp, Brutsaert et al evaluated 31 indices of ventricular diastolic function and paid special attention to measuring diastolic relaxation, stiffness, and compliance. ${ }^{13}$ Left ventricular diastolic impairment is an important pathophysiological mechanism reflecting the symptoms of congestive heart failure from hypertension, ischaemic heart disease, and cardiomyopathies ${ }^{14}$; it is considered to be a significant cause of cardiac symptoms in conges- tive heart failure despite normal systolic performance. $^{15}$

Given the fact that the ventricular filling process is complex and dependent on myocardial relaxation, ventricular diastolic suction, viscoelastic forces in the myocardium, ventricular and atrial contractility, pericardial restriction, interventricular interaction, and heart rate, the evaluation of diastolic functional indices is controversial. ${ }^{16}$

Cardiac involvement in HIV infection has two clinical patterns: $6-7 \%$ of HIV infected patients have clinically significant cardiac disease and the remainder are asymptomatic. ${ }^{17}$ Congestive heart failure symptoms are often late manifestations.

Our objective in this study was to determine the prevalence of left ventricular dysfunction in Congoese patients infected with HIV. The hypothesis was that many HIV infected patients have cardiac abnormalities which are not recognised during the course of their disease.

None of the HIV infected patients in our study had congestive heart failure. Systolic left ventricular function was normal in our patients, while in published reports $10-40 \%$ of HIV infected patients have systolic left ventricular dysfunction. ${ }^{18}$ Left ventricular wall thickness and mass index tended to be increased in the study population in comparison with normal subjects and this was significant. Wall thickening and fibre elongation contribute to the pattern of concentric hypertrophy. Septal thickness was negatively correlated with right ventricular ejection time. However, the right ventricular systolic time interval ratio in our HIV infected population was normal, suggesting that pulmonary artery pressures were not raised.

Left ventricular systolic time interval ratios were lower in HIV infected patients and negatively associated with shortening fraction, presumably on the basis of reduced systemic resistance from relative anaemia. ${ }^{19}$ Blood pressure levels were also normal. Increases in left ventricular end diastolic dimensions and ejection time were noted among HIV infected subjects and were correlated with each other. Impairment of left ventricular function should raise left ventricular systolic time interval ratios. ${ }^{20}$ Though shortening fraction was normal for HIV infected patients, suggesting normal left ventricular contractility, the velocity of circumferential fibre shortening was significantly decreased. The difference may be explained by the fact that afterload, as reflected by left ventricular ejection time, is taken into account by the velocity of circumferential fibre shortening. Despite an apparent increase in the rate of symptomatic HIV associated left ventricular dysfunction compared with the general population, the small number of cases arising from clinical referrals suggests that morbidity or mortality caused by contractile dysfunction in an HIV infected population is still relatively infrequent. ${ }^{8}$ Velocity of circumferential fibre shortening was negatively connected with haemoglobin concentration, and it was the only indicator of left ventricular systolic function that was abnormal in the HIV 
infected population - this variable may not, however, be reliable when there is significant left ventricular dilatation, ${ }^{21}$ as observed in our study population.

It has been reported that left ventricular diastolic dysfunction was present in $53.8 \%$ of 40 asymptomatic AIDS patients. ${ }^{22}$ This should be compared with the value of $85.7 \%$ of our 49 Congoese HIV infected patients with left ventricular diastolic dysfunction but with no suspected cardiac abnormalities on physical, electrocardiographic, and radiological examination.

There was significant association between the cell mediated immunity and the presence of echocardiographic abnormalities. Isovolumic relaxation time (diastolic function) and velocity of circumferential fibre shortening (systolic function) were related to CD4+ counts.

We found a decrease in VE and VE/VA ratio and an increase in VA and isovolumic relaxation time in the HIV infected patients. This means there was impairment of myocardial relaxation and filling dynamics of the left ventricle. $^{23}$

Our study, carried out in a developing country, has the limitation of not having any invasive data or information on ventricular compliance or apex cardiography. These deficiencies were compensated to some extent by the "scanner of the poor"-that is, sonographic studies obtained from rare necropsies. Necropsies on patients dying from natural causes are resisted culturally in Africa. ${ }^{24}$ The advent of Doppler echocardiography has enabled non-invasive measurement of the velocities of cardiac blood flow, ${ }^{23}$ with good correlations with data obtained by angiography ${ }^{25}$ or radionuclide studies. ${ }^{27}$ In 22 patients undergoing simultaneous cardiac catheterisation and Doppler studies, the VE/VA ratio correlated with left ventricular end diastolic pressure $(r=0.8) .{ }^{28} \mathrm{It}$ was also shown that abnormal left ventricular compliance could be correlated with Doppler indices. ${ }^{29}$ Simultaneous recordings of Doppler time intervals and the respiratory cycle have been shown to discriminate between HIV related cardiac abnormalities and pericardial disease. The possibilities for reliable noninvasive diagnosis have been discussed in detail by Hatle et al. ${ }^{30}$

In France, Coudray et al reported, as we did, the presence of early left ventricular filling abnormalities in asymptomatic and symptomatic HIV carriers with intact global systolic function, ${ }^{31}$ while Reilly et al reported a $3.4 \%$ incidence of heart failure from AIDS related left ventricular diastolic dysfunction. ${ }^{32}$

Our findings confirm English data showing that the prevalence of cardiac abnormalities is higher in HIV infected patients with more advanced disease. ${ }^{33}$ The Doppler echocardiographic indices of left ventricular diastolic function in Congoese HIV infected patients are typical features of cardiac involvement and showed development of a restrictive filling pattern. Left ventricular isovolumic relaxation time increased from HIV positive carriers to AIDS patients, and peak early velocity declined. The major abnormality was a shortened deceleration time in HIV seropositive individuals compared with the control group. The shortened deceleration time reflects the diminished compliance of the left ventricle. There was no mitral regurgitation in these HIV infected patients.

On the other hand, when no significant mitral regurgitation is present, abnormalities in left ventricular chamber stiffness and compliance caused by the cardiomyopathic process can become evident as a decrease in the peak ejection velocity, diminished deceleration time, and a decrease in the VE:VA ratio. ${ }^{34}$ In patients with documented systemic amyloidosis (which may be present in as many as $66 \%$ of HIV positive carriers on the basis of gingival and renal histopathological data) but with mildly increased left ventricular wall thickness (1.2 to $1.4 \mathrm{~cm}$ ), Klein et al reported reduced VE velocity and increased VA velocity with prolonged isovolumic relaxation and normal left atrial pressure (left atrial dimensions were normal). ${ }^{35}$ Apparently, with progression of HIV infection, the impairment of compliance progresses until it dominates the dynamics of diastolic filling and overshadows the effect of abnormal relaxation.

Some of the indicators vary with age, probably because of alterations in the diastolic characteristics of the myocardium. With aging isovolumic relaxation time is prolonged, VE velocity falls, and VA velocity increases. Our HIV infected population had no people of advanced age. The HIV infected subjects were all young and had a normal clinical, electrocardiographic, and radiological examination, excluding other factors that might modify mitral flow patterns. In young HIV infected patients from Portugal, ${ }^{22}$ the patterns of mitral flow can be superimposed on the patterns found in the normal aged population. The characteristics of the mitral flow in our HIV infected patients are not the result of an increase in heart rate, as no correlations between deceleration time, isovolumic relaxation time, and heart rate were observed. They may be the result of heart disease secondary to amyloidosis, which affects muscular relaxation and leads to restrictive physiological changes. ${ }^{27}$

The pathogenesis of left ventricular diastolic dysfunction in HIV infected patients is unknown. As noted, myocarditis, left ventricular dilatation, and concentric hypertrophy are the underlying causes of this diastolic dysfunction. Possible aetiologies include direct infection of the heart by the HIV virus and other opportunistic pathogens (Mycobacterium avium, Cryptococcus neoformans, Toxoplasma gondii) or direct involvement by a neoplastic process (Kaposi sarcoma, lymphoma) and infiltrative disease (amyloidosis, tuberculosis). In addition, such echocardiographic abnormalities explain the high proportion of AIDS patients with moderate dyspnoea, although without heart failure manifestations.

Malnutrition could explain the presence of cardiac atrophy in nine seropositive women. ${ }^{36}$ Selenium deficiency was related to cardiomyopathy in AIDS. ${ }^{37}$ 
CONCLUSIONS

We have described the echocardiographic abnormalities in black HIV infected patients from Congo with unsuspected cardiac lesions. We found a high prevalence of left ventricular diastolic dysfunction. Systolic function was normal. In a study we carried out on a sample of AIDS patients, ${ }^{38}$ significant left ventricular systolic dysfunction was detected in $85.7 \%$. This cardiac dysfunction occurred mostly after the onset of AIDS and had a restrictive pattern.

Echocardiography was a useful technique for the early detection of cardiac dysfunction in asymptomatic HIV positive carriers and AIDS patients.

1 Gottlieb MS, Schrof R, Schanker H, et al. Pneumocystis carinii pneumonia and mucosal candidiasis in previously healthy homosexual men. Evidence of a new acquired cellular immunodeficiency. $N$ Engl 7 Med 1981;305:1425-31.

2 Chaisson RE, Volberding PA. Clinical manifestations of HIV infection. In: Mandell GL, Douglas RG, Bennett JE, eds. Principles and practice of infectious disease, $3 \mathrm{rd}$ ed. New York: Churchill Livingstone, 1990:1059-6.

3 Fauci AS, Masar H, Gelmann LP, et al. The acquired immune deficiency syndrome. An update. Ann Intern Med immune deficiency

4 Bories C, Salmeron M, Modigliani R. Diarrhée et syndrome d'immunodépression acquise. Gastroenterol Clin Biol 1985; 9:321-6.

5 Brunet $\mathrm{P}$, Bolgert F, Pierrot D. L'infection du système nerveux central par le virus du déficit immunitaire humain acquis. Rev Neurol 1988;144:317-26.

6 Clumeck M, Herman P, Witt SD. Current problems in the management of AIDS patients. Eur F Clin Microbiol Infect Dis 1988;1:2-8.

7 Mayaud C, Touboul JL, Montagne V, et al. Les infections respiratoires au cours du SIDA. Rev Prat 1986;36:116976.

8 Herskowitz A, Vlahov D, Willoughby S, et al. Prevalence and incidence of left ventricular dysfunction in patients with human immunodeficiency virus infection. Am $\mathcal{f}$ Cardiol 1993;71:955-8.

9 Cegieslski JP, Kaushir R, Lallinger G. Pericardial disease and HIV in Dar es Salaam, Tanzania. Lancet 1990;335: 209-12.

10 CDC. HIVIAIDS surveillance report. Atlanta, February 1993:1-23.

11 Longo-Mbenza B, Tonduangu K, Kintoki Vita E, et al. Influence de l'infection par le VIH sur la fréquence élevée des cardiopathies à Kinshasa (Zaïre). Etude échocardiographique. Ann Cardiol Angeol 1997;46:81-7.

12 Henri WL, De Maria A, Gramiak R. Report of the American Society of Echocardiography committee on nomenclature and standards in two-dimensional echocardiography. Circulation 1980;62:212-17.

13 Brutsaert DL, Radsmarkers FE, Sys S, et al. Analysis of relaxation in the evaluation of ventricular function of the heart. Prog Cardiovasc Dis 1985;28:143-63.

14 Inouye I, Massie B, Loge D, et al. Abnormal left ventricular filling: an early finding in mild to moderate systemic hypertension. Am f Cardiol 1984;53:120.

15 Simons M, Pandian N, McInerney K, et al. Diastolic filling dysfunction in patients with congestive heart failure and dysfunction in patients with congestive heart failure and
normal systolic function [abstract]. Circulation 1986;74: 384 .

16 Wilbur YW. Evaluation of left ventricular diastolic function. Circulation 1989;79:1393-7.

17 Anderson DW, Virmani R. Emerging patterns of heart disease in human immunodeficiency virus infection. Hum Pathol 1990;21:253-9.
18 Kauls S, Fishbein MC, Siegel RJ. Cardiac manifestations of acquired immune deficiency syndrome: a 1991 update. Am Heart $\mathcal{F}$ 1991;122:535-44.

19 Abduhallah AK, Siddliqui MA, Fajuddin M. Systolic time intervals in chronic anemia. Am Heart f 1977;94:287-91.

20 Weissler AM, Lewis RP, Leighton RF. The systolic time intervals as a measure of left ventricular performance in man. In: Yu PN, Goodwin JF, eds. Progress in cardiology. Philadelphia: Lea and Febiger, 1972:155-83.

21 Bhatt DR, Isabel-Jones JB, Valloria GJ, et al. Accuracy of echocardiography in assessing ventricular dimensions and volume. Circulation 1978;57:699-707.

22 Arroja I, Azlvedo J, Carmona J, et al. Left ventricular diastolic function evaluation in AIDS patients. Information Cardiologique 1991;15:51-6.

23 Nishimura RA, Housmans PR, Hatle LK, et al. Assessment of diastolic function of the heart: background and current applications of Doppler echocardiography. Mayo Clin Proc 1989:64:181-204.

24 Hakim JG, Matenga JA, Siziya S. Myocardial dysfunction in human immunodeficiency virus infection: echocardiographic study of 157 patients in hospital in Zimbabwe. Heart 1996;76:161-5.

25 Appleton CP, Hatle LK, Propp RL. Relation of transmitral flow velocity patterns to left ventricular diastolic function: new insights from a combined hemodynamic and Doppler echocardiography study. $\mathcal{F}$ Am Coll Cardiol 1988;12:42640.

26 Rockey R, Kuo LC, Zoglibi WA, et al. Determination of parameters of left ventricular diastolic filling with pulsed Doppler echocardiography: comparison with cineangiography. Circulation 1985;71:543-50.

27 Spirito P, Maron BJ, Bonow RO. Non-invasive assessment of left ventricular diastolic function: comparative analysis diastolic function: comparative analysis of Doppler echocardiographic and radionuclear angiographic technique. F Am Coll Cardiol 1986;7:518-26.

28 Channer KS, Culling W, Wilde P, et al. Estimation of left ventricular end-diastolic pressure by pulsed Doppler ultrasound. Lancet 1986;i:1005-7.

29 Stoddard MF, Pearson AC, Kern MJ, et al. Left ventricular diastolic function: comparison of pulsed Doppler echocardiastolic function: comparison of pulsed Doppler echocar-
diographic and hemodynamic indexes in subjects with and without coronary artery disease. $7 \mathrm{Am}$ Coll Cardiol without coronary

30 Hatle LK, Appleton CP, Popp RL. Differentiation of constrictive pericarditis and restrictive cardiomyopathy by Doppler echocardiography. Circulation 1988;79:357-70.

31 Coudray N, De Zuttere D, Force G, et al. Left ventricular diastolic function in asymptomatic and symptomatic human immunodeficiency virus carriers: an echocardiography study. Eur Heart F 1995;16:61-7.

32 Reilly J, Cunnion R, Anderson D, et al. Frequency of myocarditis, left ventricular dysfunction and ventricular dysfunction and ventricular tachycardia in acquired immune deficiency syndrome. Am $\mathcal{f}$ Cardiol 1988;62:789-98.

33 Akhras F, Dubrey S, Gazzard B, et al. Emerging patterns of heart disease in HIV infected homosexual subjects with and without opportunistic study. Eur Heart 7 1994;15:6875

34 Acquatella H, Rodriguez-Sala LA, Gomez-Mancebo JR. Doppler echocardiography in dilated and restrictive cardiomyopathies. In: Schiller NB, ed. Cardiography. Philadelphia: WB Saunders, 1990:349-68.

35 Klein AL, Hatle LK, Burton DJ, et al. Doppler characterization of left ventricular diastolic function in cardiac amyloidosis. F Am Coll Cardiol 1989;13:1017-26.

36 Anderson DW, Virani R., Reilly JM, et al. Prevalent myocarditis at necropsy in the acquired immunodeficiency syndrome. 7 Am Coll Cardiol 1988;11:792-9.

37 Lafont A, Zazzo VF, Chappuis P. Are cardiomyopathies in AIDS dependent on selenium deficiency? Abstracts of the Gist Scientific Sessions. Circulation 1988;78(suppl II):411 .

38 Longo-Mbenza B, Tonduangu $\mathrm{K}$, Muvova D, et al. Etude clinique des manifestations cardiaques au cour du syndrome d'immunodéficience acquise (SIDA) à Kinshasa. Arch Mal Coeur 1995;88:1437-43. 